\title{
Taking on the Institution: An Autoethnographic Account
}

\author{
Margaret Hodgins
}

check for

updates

Citation: Hodgins, M. Taking on the Institution: An Autoethnographic

Account. Societies 2021, 11, 39. https://doi.org/10.3390/soc 11020039

Academic Editor: Pooja Sawrikar

Received: 27 February 2021

Accepted: 21 April 2021

Published: 25 April 2021

Publisher's Note: MDPI stays neutral with regard to jurisdictional claims in published maps and institutional affiliations.

Copyright: (C) 2021 by the author. Licensee MDPI, Basel, Switzerland This article is an open access article distributed under the terms and conditions of the Creative Commons Attribution (CC BY) license (https:// creativecommons.org/licenses/by/ $4.0 /)$.
Independent Researcher, H91 TX33 Galway, Ireland; margaret.hodgins@nuigalway.ie

\begin{abstract}
The over-representation of men and the under-representation of women in senior positions in academic institutions is a familier and deep-rooted problem. While gender inequality in Higher Education Institutions has multiple causes, recruitment and internal promotion practices are particularly potent contributors to inequality regimes. This paper contains an autoethnographic account based on my failure to secure promotion and my subsequent legal action. It offers a personalized account of the experience of gender discrimination, in order to illuminate aspects of the culture of the Higher Educational Institution that contribute to this problem, and the challenges inherent in changing it. The theoretical perspective includes notions of organizational culture as gendered, drawing on the works of Louise Morley and Georgina Waylen, Pat O'Connor, Louise Chappel and Teresa Rees, as well as Carol Agócs work on institutionalized resistance to change, and theories of hidden and invisible power. The paper is a personal narrative autoethnography with self-reflection, adopting an analytic/interpretive approach. Based on an analysis of publicly available documents, personal journaling and media material, I identify four themes; (1) Slow Fuse burning, (2) From indifference to resistance, (3) Fixing me/Fixing women, (4) Solidarity. I conclude with reflections on the importance of seeing gender inequality and discrimination when it occurs and the importance of data in creating greater transparency that facilitates 'seeing'. I also consider the importance of female anger and the importance of female solidarity.
\end{abstract}

Keywords: gender equality; organizational culture; institutionalized resistance; higher education

\section{Introduction}

The over-representation of men and the under-representation of women in senior positions in academic institutions is a familiar but also a deep-rooted problem. Women disappear as one moves up the organizational hierarchy; in the EU-28 in 2016, women represented $46 \%$ of grade C academic positions, $40 \%$ of grade B, $24 \%$ of grade A academic positions, and $22 \%$ of heads of $\mathrm{HE}$ or research institutions [1]. While gender inequality in universities is multi-causal, the processes and practices that form the basis of recruitment and internal promotion are particularly important in the creation and maintenance of inequality regimes. Irish universities have never performed well in the equality stakes when it comes to senior academic positions. Although the issue of the very low representation of women was raised as far back as the 1980s, little action was taken, with those academics researching inequality in academia and raising the issue essentially voices in the wilderness. An Act in 1997 (Universities Act) (http: / / www.irishstatutebook.ie/eli/1997/act/24/enacted/en/html (accessed on 20 April 2021)) obliged Universities to develop equality policies and monitor staffing figures. However, progress was glacial. In 2011, Ireland still had the lowest proportion of women at the professorial level when compared to other EU states [2]. By 2016 women in full professorships in Irish universities amounted to only 21\% [3], although this has since risen to $26 \%$ [4], which in actual numbers represents c. 56 women, and a rate of improvement of less than $2 \%$ per year.

This article draws on experiences within one Irish university, pseudonymized here as the Green University, which has served for some time as a "worst case" exemplar. Based on the evidence from annual gender profiles for the (then) seven universities [3-6], 
the Green University has consistently trailed behind others as regards the proportion of women in senior academic positions, only passing the national average for percentage of female senior lecturers c. 2016 [5] and remains well below the national average for female professorial positions [4]. Gender inequality was brought into sharp focus following two landmark Equality Tribunal rulings in 2014 against the Green University. These stimulated considerable change in higher education, including, rather belatedly, the Green University itself. This account draws on my experience of events that led to change. (For a detailed account of changes in the sector, see $\mathrm{O}^{\prime}$ Connor and Irvine (2020))

One of the Equality Tribunal cases was that taken by Dr. Joan Francis, a Lecturer in the Green University, (the names of individuals and institutions that are identifiable have been pseudonymized), who was found to have been discriminated against on the basis of gender in an internal promotions competition in 2008, where 17 candidates were promoted; 16 men and 1 woman. Dr. Francis was one of the six female applicants shortlisted but not appointed in the promotion competition [7]. This competition has been the subject of much media discussion due to its failure to contain even the most basic safeguards against discrimination. Dr. Francis donated her award to the other unsuccessful five women who subsequently took cases against the university. I was one of the five women, and my perspective, presented here in the form of an autoethnographic account and based on having taken legal action, may provide insights to the culture that creates and sustains this problem.

\section{Theoretical Position}

In my first lecturing post, I was required to teach a course on organizational behavior. Having been either self-employed or working in community organizations prior to taking the post, I was on a rapid learning curve, figuring out how things worked in the College, who was who, and what mattered. In lecture preparation, I encountered the concept of organizational culture that resonated with my challenges in "learning the organization". It fascinated me then and still does. I immediately recognized it as a powerful influence on behavior in organizations, but the more I taught it and as my organizational experience extended, I came to see it to be more than "an influence", now seeing it as the essence of an organization. As I witnessed and encountered gender discrimination, I wondered vaguely about the possibilities that cultures are gendered, but it was only when I stumbled upon the notion of the gendered organization that two important jigsaw pieces clicked into place for me.

Thus, I approach this article drawing on both organizational culture and feminist institutionalism. Feminist institutionalism argues that gender is a process, and that the norms and assumptions that operate in institutions are gendered [8,9]. Gender is seen to operate at the individual, interactional or organizational level and the systemic or cultural level $[10,11]$ in a way that continually recreates and sustains gender inequality [9].

Different ontological assumptions can be found in the organizational culture literature; an objectivist assumption that sees culture as an entity that can be identified, described and measured by an instrument independent from it, or a subjectivist assumption that presupposes culture cannot be concretely measured but only interpreted [12]. The former can be described as something the organization "has", the latter, which underpins this study, as something that an organization "is" [12-14]. In this view, organizational culture is inferred from symbols and behaviors, and while influenced by external events, these interact in an idiosyncratic manner with internal forces making culture unique in any one institution or organization [12,15]. If culture is something the organization "is", it follows that it is not divorced from structure; culture and structure are caught in dynamic reciprocation-culture influences structure and structure reinforces culture.

As organizations are gendered, culture is gendered, encoded in formal and informal practices and networks [16]. The beliefs and assumptions about acceptable and "natural" forms of behavior for men and for women, what Chappel terms the "logic of appropriateness" [8], give rise to the structures, processes and practices that maintain men in positions 
of power and legitimate women's lower positions in the organizational hierarchy $[8,17]$. Assumptions and taken-for-granted beliefs have been identified in studies of higher education institutions (HEIs); for example, gender essentialism and management not being the "proper" place for women, $[18,19]$, women's failure to secure promotion being due to "deficits" in their self-belief or presentation skills [16], and that women are not competent enough for senior positions that require tough decisions [20]. Gender is encoded in the formal, overt structures and policies but also the informal and everyday practices of organizations $[16,17,21]$. Even when organizations are overtly committed to equality, the exclusion and under-valuing of women operates in the myriad everyday behaviors, interactions and exchanges, hidden, subtle and sly. Like fog, gendered culture creeps around corners, seeps up through drains, surrounds us, and yet, because we are within it, we often fail to see it.

Addressing gender inequality in HEIs requires organizational change, which, in my understanding, is fundamentally culture change, and where culture change is essential to creating and maintaining structural change. A plethora of change management models exist, to the point that they can be confusing and contradictory [22], and which may, in part, explain why organizational change is frequently described as difficult to bring about [23]. Much of the organizational change literature pertains to change driven by economic forces or factors. It is predominantly prescriptive, advocating a managed, staged approach based on rational, strategic models [24,25], and focuses on change driven by senior management requiring behavior change in employees, such as middle managers, and factory or floor workers, arguably a masculinist view. Less commonly found is change management in the context of a change in attitude and mindset being required by senior management, or where an institution is required to change for moral or ethical reasons as opposed to economic viability, both of these conditions being met in the need to change HEIs to achieve gender equality.

When I first encountered Agócs' work on institutionalized resistance to change, another piece of the jigsaw fell into place. The typology she describes spoke to me about my personal experiences of a long drawn-out conflict with my employer. While I encountered resistance, I could not quite pin it on any one person or process. However, the concept of institutionalized resistance to change offered an epiphany of sorts. Agócs (1997) [25] presents a critical view of established approaches to organizational change. She argues that it is necessary to look at resistance to change and to the form that resistance takes. She describes resistance as "a pattern of organizational behavior that decision makers in organizations employ to actively deny, reject, refuse to implement, repress or even dismantle" proposals for change [25] (p. 918), which can become "embedded in and expressed through organizational structures and processes of legitimation, decision making and resource allocation" (ibid., p. 918). Agócs argued that much of the organizational change literature is, effectively, power-blind, a situation that has not changed since her work in 1997. She maintains it fails to "address the ways in which gender and racial equality are built into the structures and cultures of organizations" (ibid., p. 919), and how resistance can be enacted by those with power in an organization, who see change as a challenge to their power and the privileged position they hold as a result of that power. While resistance to change has been studied in a number of contexts, including higher education (e.g., [26,27] Agócs' focus on institutionalized resistance is particularly pertinent in the context of victim-led litigation against the organization), change is more likely to be resisted than adopted by the powerful in an organization, when they are more likely to have something to lose from a change in the status quo. Nowhere is this more evident than in the case of almost exclusively male senior management being required to change structures and processes in order to share that power with women.

For me, this pulled in the final piece of the jigsaw. As explored in my own work on workplace bullying [28,29], I saw linkages with power theory, in particular the notion of hidden power. Hidden power is seen to be an advance on overt or visible power, and is explored by Bachrach and Baratz [30], and latterly, Lukes and Gaventa [31,32]. In this view, the powerful not only exercise power in the making of decisions in a visible or 
overt way, but a power is exercised to set the "rules of the game" [30] (p. 952) to limit what decision making takes place, and to prevent certain problems being even vocalized or exposed. In this articulation of power, the powerful actors predetermine the agenda. This has the effect of protecting and reinforcing their powerful position. The decision to approach promotional schemes as competitions, and the decisions around the selection and weighting of criteria for those competitions, are decisions that favor men, made by a management structure that is almost exclusively male. Both now and at the time of these events, the President and the Deputy President of the Green University are both male, as have been all their predecessors. Consistently, from 2004 to 2020, all college deans have been male.

In organizations, powerful actors can categorize certain issues, such as inequality, as non-issues by subtle means such as insisting on very limited parameters regarding the causes of and/or solutions to certain problems (Sadan, 2004c). Presenting the cause of gender imbalance in senior positions as due to women failing to secure promotion because they lack confidence or self-presentation skills, or need "leadership" training inevitably frame the solution as helping or "fixing" women [33] and constitute informal and largely hidden power exercises, also identified by Agócs as forms of institutionalized resistance [25]. They serve the interests of the powerful in the context of the need to maintain the myth that promotional competitions are meritocratic $[16,34]$.

A third dimension of power attributed to Lukes [32] exists where its exercise is not even perceived - where it is seen as the natural order of things-for example, that women will not do as well as men in promotional competitions, or men are more entitled to leadership and senior positions, and therefore, that there is no need to challenge patriarchal structures.

\section{Materials and Methods}

There are few of us who do not have a "lived experience" of a gendered organization. Yet, also, few recognize it, in the way that fish probably do not recognize water. Sometimes it takes specific events or experiences to expose the medium in which we operate on a daily basis, when the scales fall from our eyes and we see things as they really are. There are many scholarly accounts of the gendered organization and also many prescriptions for cultural change, yet personal accounts offer a perspective that complement and illuminate intellectual discourse.

The interpretive approach to studying organizational culture employs qualitative methodologies such as ethnography, case study or narrative, and allows, indeed requires, that researchers are "insiders", studying the culture from within, with reflection as part of this process $[12,13,35]$. Autoethnography, which has been described as using yourself to get to a culture [36], is therefore an appropriate method to understand that culture and the difficulties in bringing about change within it. Similar autoethnographic studies have been conducted on the experiences of female administrators of color in the academy, highlighting their constraints put on time and the limitations on their authority [37], experiences of everyday sexism that turn into oppression because of silencing [38], and the experience of a senior academic in employing a pragmatic inclusionary strategy to achieve gender parity [39]. I offer here a personalized account that draws on my experience in litigating against my employer on gender discrimination grounds that I hope extends understanding of the gendered organization, how it is maintained and how change is resisted.

Autoethnographies have been classified in various ways. I identify this as a personal narrative [40] with self-reflection, in which I have adopted an analytic/interpretive approach [41]. Autoethnography can been criticized for the possibility of bias [42] due to the potentially distorting effects of recall [39], the focus on the self [43] and more generally, as insufficiently scientific. The position taken here is based on Ellis et al.'s claim that autoethnography as a method attempts to disrupt the binary of science and art [40], and can offer a valid contribution to understanding the social by prompting reflection on realities that may not have been considered before [43] or obtainable in any other way [39]. I have attempted to maintain theoretical rigor, while being both analytical and emotional 
in an account of personal and social phenomena [40]. As recommended by Ellis et al. [40], relational ethics were addressed in respect of various university personnel through altering identifying characteristics such as name and title.

Throughout the process of litigation, I kept notes in the form of frequently writing text "to myself" as a sense-making and even sanity-maintenance exercise, over the four years between lodging papers and a period of reflection after settlement. This also served as a way of dealing with frustration and anger. I draw principally on these (62 handwritten pages, 54 pages typed summary of experience after settlement) as well as documentation gathered in the course of the litigation and publicly available documents (e.g., material on the Green University website (c. 20 pages)). The cases were unusual in that they received considerable media coverage, orchestrated by an activist campaign, which generated public debate on the topic, and I also draw on these in my analysis.

Based on an analysis of publicly available documents, personal journaling and media material, I identify four themes: (1) Slow Fuse burning, (2) From indifference to resistance (3) Fixing me/Fixing women, (4) Solidarity.

\section{Background}

I started working at the Green University in 1995 on a temporary contract as I completed my PhD, and secured a permanent Lecturer position in 1998. My post initially included the directorship of an Adult Education programme of c. 300 students, some years later the directorship of an M-level programme (2002) and also undertaking Acting of Head Discipline for c. 9 months. In 2006, a senior lectureship was advertised and I applied, but was not deemed suitable. In 2008, I applied through the internal Senior Lecturer Promotions Scheme (SLPS) (the academic career structure at the Green University has four main points: lecturer, senior lecturer, personal professor, full professor), and although shortlisted and interviewed, I was not appointed. I was informed that although I was suitable, only the top-ranking applicants were promoted and I was not among them. Some months later, the news leaked out that of the 17 people promoted, 16 were men. I made an appointment with a (then) member of the HR staff, aware that the rate of success is what matters, and requested information on the gender breakdown of applicants and shortlisted applicants. This request had to go to a senior member of academic management. I was then told I would be given the breakdown, in confidence, if that senior person could be told who requested them. This "requirement" was not listed in the promotional documentation-a true "Calvinball" moment (referring to the game played in the cartoon strip Calvin and Hobbes-Calvinball has no rules, the players make up their own rules as they go along) as the powerful decided on the "rules of the game". These figures have since been widely published, both within the university and publicly, and can be seen in Table 1.

This was the point at which Dr. Francis (who was also shortlisted but not appointed) told took her case to the Equality Tribunal. Her case ran for five years. In 2014, the Tribunal ruled that Dr. Francis had been both directly and indirectly discriminated against on the basis of gender in an internal promotions competition in 2008:

The Equality Tribunal held that the entire interview process was "ramshackle". Amongst the issues raised by the Tribunal was the failure to provide training for interviewers, the lack of an agreed marking scheme, no pre-meeting of the interview board, no questions agreed in advance of interview, no individual assessors' marks retained, and that the external interviewer's suggestions were ignored. In short, though on paper the scheme appeared fair, the "implementation fell short of best practice in recruitment" [7].

Between Dr. Francis taking her case and the final ruling, the SLPS (normally on a biennial cycle) was frozen due to an Employment Control Framework (in place for the higher education sector, to reduce the costs of the public sector pay bill during the economic crisis) in operation in the public sector. It reopened in 2013, some nine months prior to publication of the Francis ruling. At this point, the outcome of the 2008 competitions was well known and some changes had been introduced; more women on the assessment panel (although not fully gender balanced), gender equality training for the panel, and 
a minimum quota for female promotions (33\%). The scheme in 2013 involved 19 criteria relating to "Research and Scholarly Standing", "Teaching and Learning", and "Contribution to School, College, University and Community". The criteria were scored by a panel of senior staff (max. score 300), and evaluated by two or three external subject experts. Most appeared, at face value, to be appropriate for promotion (student feedback, teaching approach, research funding, scholarly standing, research leadership, etc.) but the standards to be attained, and hence the application of scores, involve judgments that are highly subjective and, therefore, open to bias-gender, nationality, ethnicity, age, any or all could operate. This particular account is concerned with gender bias, which was principally what I, as a white Irish heterosexual woman, experienced.

I (and the other six women, including Dr. Francis) applied again for promotion to senior lecturer in 2013. By that time, I had been appointed Head of School, although still at the Lecturer level. When the results of the competition were made known, from a pool of just over 100 applicants, 28 were appointed, 9 of which were women-bang on the minimum quota. Six men who were unsuccessful but shortlisted in 2008 were still at the Green University and four of these were promoted in 2013. Yet, neither Dr. Francis nor the other five women (this includes me) who had been shortlisted in the 2008 SLPS were promoted in the 2013 SLPS. Four of the women appealed that decision, but their appeals were not upheld.

Soon after the results of the 2013 competition were becoming known, Dr. Francis won her case on the 2008 round and the details were made publicly available. The Tribunal judged her to have been discriminated against on the grounds of gender and the university was instructed to promote her and award her compensation of EUR 70,000. The five "unpromoted" women sought meetings with university management, but these were to no avail, and we subsequently, if reluctantly, took legal cases against the university. We were prepared to mediate but the offer was not taken up. A campaign was launched by supporters, people committed to social justice issues, some within and others outside the university, to draw attention to the injustices in the scheme and to raise funds for our actions. The university engaged in a PR campaign to demonstrate its commitment to gender equality, but insisted that it could not promote us on foot of the Francis ruling, as the ruling only instructed them to promote Dr. Francis.

A court hearing in Spring 2016 took place in order to gain access to relevant documents to make our case, and in May 2017, prior to another court date in which the university raised a number of pre-trial issues, we were then called to mediation. Meditation collapsed in July 2017, and immediately after, another SLPS opened up. Four of us applied again and only one was successful. It was not until July 2018 we reached an out-of-court settlement, which included promotion for the remaining four litigants. Twenty-three years after starting at the Green University, and almost 4 years after taking legal action following a promotions competition publicly reported as "ramshackle", I was promoted to a senior lectureship.

Significant change took place at the policy level as a result of our cases, including a National Review of Gender Equality in Irish Higher Education [7], the introduction of a specific initiative for women-only Professorial posts and the Athena Swan application initiative [44]. Change was also prompted within the Green University, including dedicated Equality Diversity and Inclusion structures, supports and initiatives for women, and revisions to promotional processes. Changes in the gender profile of senior staff have resulted, albeit at a slower pace than other Irish universities [45].

\section{Results}

\subsection{Theme 1: Slow Fuse Burning}

When I look back over the course of these events, I criticize myself for being so slow to act. Why was I so blind, and why did I fail to take action? Why did I not rail against the appalling lack of opportunity for women in the university at an earlier stage? I can find some answers when I consider my positioning; however, I can also see (now) that the switch from non-action to action was not a sudden off/on switch but in fact was a 
slow fuse burning. I recognized discrimination, but failed early on to see how this was underpinned by a gendered organization - gendered structures, practices and policies that perpetuate unequal power rewards and opportunities, and which reinforce and reproduce gender inequality [9]. The transcript was hidden [16], but as time went on, the gendered organization revealed itself.

Up to revelation of the outcome of the 2008 SLPS (16 men, 1 woman promoted: ie $50 \%$ of shortlisted men promoted, $7 \%$ of shortlisted women), while aware in a general way that gender discrimination operated (I only had to look around me; at that time, only 10 of 100 professors were women), I viewed it as an unfortunate fact of university life, evidence perhaps of the normalization of the gendered nature of the organization. I certainly assumed my workplace was no different to other Irish universities, and that since we had had equality legislation in place for 8 years, assumed too, that the situation was bound to improve. Of course, it was not known then that the Green University was the worst in Ireland and almost the worst in Europe (only Malta had lower numbers of women in senior posts), until the publication of the Equality Tribunal ruling. This triggered the creation of a national Gender Equality Task Force and the publication of figures for each university, revealing the Green University's place at the bottom of the Irish league table of representation of women in senior academic posts. Additionally, the actual results of the SLPS were not made available to staff generally, only a short paragraph summarizing the combined achievements of the successful candidates ("the successful candidates had between them 250 journal articles, 3 books, 24 PhD students", etc.), a bizarre and useless narrative, with no mention of gender. The polarized outcome regarding gender imbalance was only known because it was leaked. This underscores the importance of access to data. At a more sinister level, this shrouding of the results of promotional competitions in secrecy resonates with Morley's description of hidden transcripts and how they contribute to the operation of gender discrimination in higher education [16]. Secrecy about promotions hides gendering which can then function to maintain masculine hegemony [10] and to silence victims. Morley's analysis of micropolitics in the operation of gender inequality is also illuminating when I consider the stipulation to identify myself in order to receive information that should have been made available, not just to me but to all staff members. This was not a formal policy but an informal "rule" introduced simply to intimidate and ensure the status quo was not challenged. In this, it also functions as an example of hidden power [46]. Hidden transcripts are essentially hidden power.

I considered contacting my trade union but did not. I had not at that point in my career seen myself as a "union person", which I now interpret as not being prepared to take on the system. I briefly considered legal action but made a conscious decision not to pursue an action as it seemed daunting, and justified this decision with the thought it might result in my being victimized in the next promotions round. I did see the operation of power insofar as I was less powerful than the senior managers in the university and they were in the "giving seat" when it came to promotions. Although this annoyed me, I still sought rationalizations for not acting. Additionally, I partly believed I had not done enough to get promoted, internalizing the messages handed down to me by the powerful men in the organization, an example of gender operating at the individual level [10]. The fuse had caught however, and started to burn.

I was naïve about the reality of organizational power, particularly and the lengths to which the powerful men at the top of the organization would go to hold onto their power. For me, as a psychologist, it was about stereotypes that needed to be corrected, although even sociologists too can, at least initially, blind themselves to organizational power, as $\mathrm{O}^{\prime}$ Connor records [39]. I also assumed that the injustice was simply delayed justice; even though I believed I should have been promoted in 2008, I believed I would be a few years later, and it was better not to rock the boat. It was widely believed that it took two attempts to secure a senior lectureship, an example of another hidden transcript; an organizational culture that rewards obedience and the ability to silently wait for the next turn. This transcript is likely to be gendered, although at this time, there was no 
transparency around the gender breakdown of success on first, second or third attempts to secure promotion. However, given the consistently higher success rates of men in these competitions (citation will identify the university, so supplied in confidence to the editor), it seems likely that they do not have to wait long or at all. "Justice delayed is justice denied" was not a phrase I was familiar with then.

In not rattling my cage, I believe I was behaving like "a good girl", the unsurprising outcome of a religious upbringing in a traditional family. However, I had also internalized the gendered logic of the inappropriateness of a woman of fighting the system [8]. (As I write this, I can hear my father's voice in the echo chamber of memory sorrowfully describing a neighbor, whom he nicknamed Mrs. Win-the-War, as always "fighting with people".) I would not have described myself at this point in my life as a fighter, or as the one who would raise the flag. However, as events unfolded, I became angry.

As this anger bubbled to the surface, I started to "see" organizational power, and how the organization was deeply gendered. When I found that I was unsuccessful again in 2013, despite being appointed as Head of School, a post that is typically taken on by Professors, I really began to see the way the organization was run by men, for men. In the 2013 SLPS, three Heads of School entered the competition, only one of which was male. He was promoted and the two women were not. However, when I realized that all of the six women who were shortlisted in 2008 were not promoted in 2013 (disclosed by the campaign listing people in alphabetical order, giving their 2009 promotion status and where they were at time of compilation), yet five of the seven shortlisted men were promoted, I was truly angry. Additionally, one of the promoted men (in 2008) was not actually eligible for promotion. Then, I was furious. No one should have had to take legal action to demonstrate that they were discriminated against in a competition where a woman only had a 7\% chance of success, and a promoted man was ineligible. As Quinlivan points out, these facts of the case alone were sufficient for Dr. Francis to meet her burden of proof [7].

I decided to take legal action. From seeing the organization as relatively benign, if unjust, I came to see it as an aggressively defended stronghold that had to be challenged. I am reminded of optical illusions where, when one "sees" the other view, one finds it very hard then to go back and see the first view. I could not see the "benign organization" image. It was illusory. The anger burned and I embraced it. It energized me and kept me going through what proved to be four very tough years. I told Joan at the start that I would rather gnaw off my own arm than back down. The four years were very difficult, but whatever else I did, I did not waver. The fuse was well lit at that point and in fact, the response from the university served to keep it alight rather than blow it out.

\subsection{Theme 2: From Indifference to Resistance}

When one takes legal action against one's employer, it would be naïve to expect the institution not to defend itself. I was not that naïve and I anticipated a battle of sorts. However, the extent to which the institution was prepared to go to avoid or at least minimize change initially surprised me, as did the personalized nature of the defense. Yet, I was also surprised that I was surprised. I had plenty of evidence that the university devalued women to the point of comedy. A cartoon that appeared on the Internet at the time (a Facebook page portrayed these cartoons, unauthored but widely believed to target the Green University) seemed to capture the perceived mindset of management at the Green University (see Figure 1).

I spoke to a lot people over the course of the litigation, many of who offered perspectives on how the institution might, should or could behave in the situation. The one that stands out starkly in memory was the colleague who simply said "You've called it. Now its Game on".

Many people believed that in the context of a legal precedent and considerable media attention, opportunities would be sought to quietly resolve the matter. Most of the litigants had appeals lodged and this would have been an opportunity to overturn the decisions of 
the 2013 SLPS, albeit a morally suspect solution. The management of the Green University had been aware of its poor performance in terms of the representation of women in senior positions since 1989. (In 1989, an Equality Committee was established by the Academic Council which then commissioned a report to consider the position of (the university) regarding the implementation of the recommendations of the Higher Education Authority report (1987) on Women Academics in Ireland.) Theories of organizational change typically argue that changes occur in response to situations that cause problems for the organization, potential loss of income or compromised service or dissatisfaction a logical response [47]. However, when problems in an organization challenge the position of the powerful, it is more likely that change will be resisted, as argued by Agócs (1997) and certainly evident in this case.

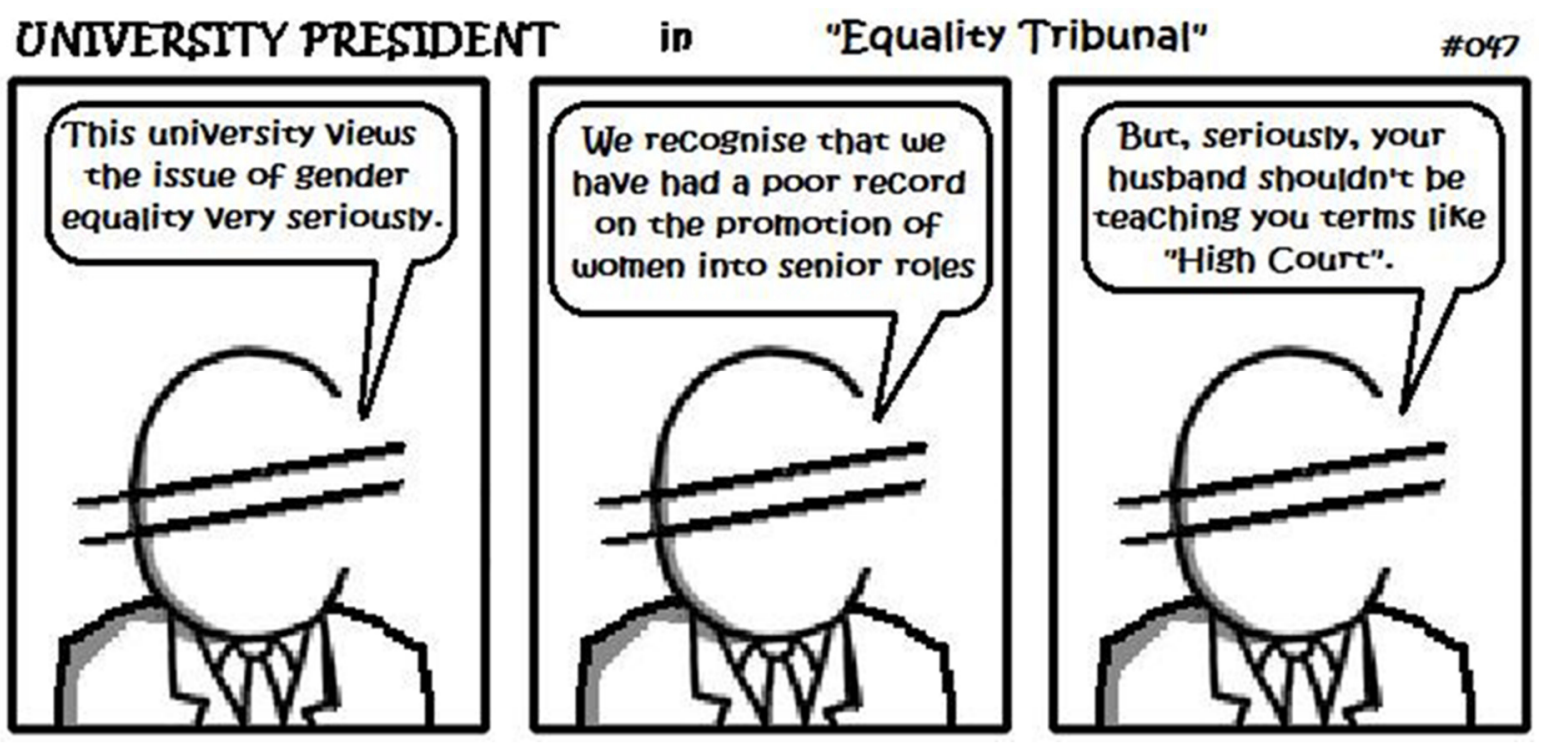

Figure 1. Cartoon on 'uniprez' Facebook site. Source: https://www.facebook.com/uniprez/photos/795934563799913 (accessed on 25 April 2021).

Based on my experience of this situation between 2009 and 2017, the Green University clearly engaged in institutionalized resistance. Agócs (1997) describes institutionalized resistance as a cycle of processes and behaviors that operate and have impacts at two levels: the organizational and the individual. As I negotiated the rapids of legal action against my employer, I witnessed a number of forms of institutionalized resistance, at both levels. Agócs argues four stages of resistance, although based on my experience, I would suggest a pre-stage: indifference.

Initially, the university was alarmingly indifferent, apparently not even seeing the need to resist. The gendered culture may have arrogance in the weave of its fabric. In the wake of the 2008 SLPS, a report was issued by the SLPS panel, overviewing its work during its term of appointment. It made only two recommendations for the future, neither of which were to do with gender. The only comment on gender was in respect of the data (provided here in Table 1) simply recommending that the university "consider" the information contained therein with due regard to practice and procedures in other universities (Report of Senior Lectureship Promotions Board (2005-2009) to the University governors). Their indifference reveals a complacency and sense of entitlement, unshaken by a promotion round in which their female colleagues had only a $7 \%$ rate of success, and a striking example of the naturalization of masculine power advantage [8]. 
Table 1. Green University SLPM results 2008 round.

\begin{tabular}{ccc}
\hline & Male & Female \\
\hline 47 applications received & 32 & 15 \\
\hline 30 short listed & 23 & 7 \\
\hline 17 successful applicants & 16 & 1 \\
\hline
\end{tabular}

The first form of institutionalized resistance, according to Agócs [25], is denial of change, which includes attacking the credibility of the change message and of the change messengers. These attacks may be directed toward undermining the content of change or toward the silencing, marginalizing or sanctioning of those that advocate change. For example, defining a systemic issue as a conundrum is a form of denial [25], and this certainly took place at the Green University. There was disquiet within the university at the outcome of the 2008 SLPS, and this was voiced at a number of meetings. Some senior members of the academic staff raised concerns about the outcome of the SLPS, and suggested there may be a need to explore deeper structural issues. However, two senior staff members on the panel, both male, claimed to be baffled at the result, and sought to reassure everyone that the panel were not at fault and defended the process. They claimed to be "at sea" as how to explain the outcome. However, they were not really interested in finding landfall. It is evident from the minutes of this meeting that the Chair of the meeting had the final word, and therefore, the power to accord legitimacy to this interpretation of events [25].

Denial is a layered concept. Another manifestation is the need to "prove" the case that gender inequality exists [25], as if promoting 1 woman and 16 men somehow was insufficient proof. Although the need for change was initially denied, the university management (almost exclusively male at this time) later denied this. As part of their denial that they denied the need for change, the Green University commissioned four separate reports on gender inequality between 2009 and 2016. The men doth protest too much.

Discussions with trade unions resulted in the setting of a one-third female quota for the 2013 SLPS, not a 50\% quota which serves as yet another demonstration of resistance. What surprised me was that while many people thought this was an acceptable figure for a quota, others actually thought it was wrong, as it implied that people would be promoted "because of their gender". That people had been promoted because of their gender for years was a truth too unpalatable to admit, and therefore easier to deny, and consistent with Agócs' claim that not to expose oneself to disturbing information about disadvantage experienced by others is another facet of resistance [25].

At the individual level, as I pursued my actions (two actions, one on each SLPS round (2008, 2013), I had personal, and hurtful, direct experience of denial. Around this time, the university created a series of web pages on "gender equality" outlining the summary points on the Tribunal ruling with FAQs about the legal actions. Soon after the pages were released, a meeting was called for the Deans and Heads of School. As a Head, I was at this meeting. A senior (male) manager went through the content of the pages in an attempt to reassure the meeting that they were doing everything they could to promote gender equality, but this did not include promoting the five women who had not been promoted in the 2013 SLPS. He said dismissively, as I sat in front of him, that he could not understand our position. This was very upsetting, yet I did not feel I could speak, as the meeting was about the general situation, not about me. Another unwritten rule-at such meetings, matters are discussed objectively, not personally, especially for women (never be hysterical, etc.). I was intimidated by the behavior but also the practices of the gendered organization, operating here at an interactional level [10]. Denial, literally, to my face was hard to take, and this meeting was a particularly low point for me.

At other times "denial" messages were given in similarly direct fashion; sometimes "we" (meaning women) just have to accept that we were not promotable, to be patient as "these things take time", that, as the university had put a gender quota in place in 
2013 and trained the panel, the 2013 SLPS was fair and robust; how could be not be? The most explicit example of denial was the frequently voiced justification for inaction that the Equality Tribunal only found in favor of the plaintiff and could not, therefore, be applied to any other person, despite the Tribunal ruling articulating serious criticisms about the process. This piece of theatrical resistance was issued in an all staff e-mail and published on the university website, along with a list of claims made by the plaintiff that were not upheld in the ruling. The five points that the Tribunal officer was said to have "rejected" (she actually said they needed more research) were the only points listed on the web site. In the Ruling, they were listed as 1 of 13 points. The 12 other points in favor of the plaintiff were not listed.

The final form of resistance in Agócs' hierarchy, and one that organizations often do not have to enact if the denial and refusals to accept responsibility have worked, is repression-action to dismantle change that has been initiated. One such example can be found in this case. The campaign to support the litigation had been very active, itself subjected to attacks on its credibility and the legitimacy of its arguments. Coincidentally, an anonymous cartoonist had been issuing subversive cartoons about the impact of the increasingly neoliberal ideology operating in the university, prior to the litigation. He or she had turned their attention to gender issues. The campaign and the Student Union organized an exhibition of these cartoons on campus. In what was later described as a great own goal from the university, the exhibition was removed during the night, although reinstated the next day when the media publicity reached crescendo.

The impact of this resistance was complex. At times hurtful, I retreated to lick my wounds. However, it was also infuriating, and stoking greater depths of rage, which fueled me for the ongoing litigation. The more I felt challenged on the truth of my experience, the more I dug in. At times it felt very personal and yet it was also obvious that the university was fighting at a more generic level. In terms of resistance, it was talking out of both sides of its institutional mouth. Quotas were in place for the next promotion round but not as high as $50 \%$, surely a basic requirement for an organization committed to change; a Gender Task Force was created which had only one real expert on gender; a report on scoring errors was commissioned but not released to the Trade Unions or to individual under Freedom of Information. When the campaign publicized the fact that the Academic Council at that time was $81 \%$ male, the provenance of the statistic was queried. Regarding the substance of the claim, a committee was created to investigate (i.e. count) and draw up proposals for change.

\subsection{Theme 3: Fixing Me/Fixing Women}

Neoliberalism values competition, metrics and financial profit over collective interests, cooperation and community (O'Connor et al., 2019), and Irish universities are no exception to the encroachment of this global ideology. Competitiveness is at the heart of neoliberalism. Promotional procedures that are run as competitions require that candidates provide evidence of "excellence" across a range of performance indicators. However, both excellence and merit are socially constructed and neither is gender neutral [19,48]. There is no consensus on exactly what constitutes excellence in the context of evaluations in higher education [49]; those who are charged with the defining of excellence are almost always men, and activities that men undertake are invariably considered more "excellent" than those undertaken by women [19]. Men are more likely to be deemed excellent, even when the achievements between male and female academics are comparable $[18,49,50]$. (For a more detailed discussion of excellence as a gendered construct, see O'Connor, 2018) The refusal to recognize the gendering of excellence leads universities to find ways of "helping" women to better compete in the excellence market. Rather than fix the bias in the system, the favored solution is to fix the women. Addressing systemic gender inequality through the design of training and mentoring initiatives for women to help them be more successful in applying for promotion is also another form of resistance, insofar as it is a refusal to take responsibility for dealing with organizational culture change [25]. 
Most women who have worked in HEIs over the past 20 years will have witnessed the many faces of "fixing the woman" (training courses, mentoring, 'dress for success' advice, leadership initiatives, CV clinics). Although critiques of these strategies are plentiful, the personal impact is rarely documented. The Green University was happy to provide a number of such initiatives, which I dutifully attended. I would sit through the sessions, juggling fury with fear; fury that women's applications were seen as the problem, alternating with fear that maybe I was still not doing the "right things" or selling myself properly.

The "you need fixing" message was pointedly reinforced in the feedback provided after an unsuccessful application. It was expected that one sought feedback from a senior member of the Promotions Panel, yet another gendered informal rule devised by the powerful [8], unquestioned in its presentation as "helpful", and part of the subtle game of power relations. To go for feedback implied capitulation to the doctrine of needing to be fixed.

My feedback session after being turned down in the 2013 SLPS, was singularly one of the most upsetting meetings in my career. It was deeply offensive in its dismissiveness and inattention to the import of this promotion to me, especially as a Head of School. The letter inviting me to the session requested I invite my Head of School (to assist with my plan for the next promotion). I pointed out that I WAS the Head of School. A Dean (male) attended on the day, with a senior member of the panel (also male). They did not have my scores. I was told I would have to request those separately. They had a short paragraph about each area (Teaching, Research, Contribution), which they read aloud and then handed to me. The comments were very vague: must do more, seek advice about $\mathrm{CV}$, and focus on publications not presentations. Apparently, I was then expected to thank them and request their expert advice on a plan. This did not happen. I let the two men know. As they edged their seats back from me, I told them I was insulted, I was humiliated before the four Heads of Discipline in my School, who all outranked me; in short, I was furious. When I later received my scores, I saw that I had dropped points, between the 2008 SLPS and 2013 SLPS from 236/300 to 156/300. I wrote to the Chair of the SLPS panel outlining what I had achieved in the past five years, under each heading and asking him to explain why my scores dropped so dramatically. I felt it beggared belief. Despite taking on Head of School and maintaining research and teaching activity, I was down 80 points from my previous application. If the system had been robust and fair, even if I had been in a cryogenic sleep between 2008 and 2013, I would have received similar points. The panel member dismissively told me to go and discuss it with a senior line manager. When I did so, he (again, a man) was mildly uncomfortable but kept focusing on what I could do for next time. It was all about fixing "me". As events unfolded and the university was the subject of opprobrium in the media, a senior member of management admitted to the media that "we have problems in this University with promotion rounds". He made it sound as if it were a defect in the plumbing.

While in litigation, I applied again in the 2017 SLPS, only to be unsuccessful again. The feedback was issued in letter, not an interview (perhaps to protect the Chair). This time it was recommended I undertake a Certificate in Teaching and Learning (despite 25 years of teaching), that I "secure more funding as principal investigator, and to publish more original research in high impact journals as lead author" (I was lead author on two-thirds of my 34 papers). The Promotions Board acknowledged that as Head of the School, I had "played a critical role not only in the School but also in the College of X and in the wider University" yet "more exemplars that demonstrate the impact of the candidate's extensive contributions would have strengthened this section of the application". When, I felt, will I have done enough.

The constant and cumulative effect of working in an environment in which one is always second best, and where one cannot trust the processes to be just or fair, or even transparent, has potentially profound effects in terms of a sense of self, morale and wellbeing. Professional identity forms part of our self-concept. "Identity work" [51], described as "the capacity to keep a particular narrative going" [52] (p. 54) is facilitated by consistent and authentic approval of others. In a regular, non-traumatic working environment, it is 
assumed that self-identity proceeds in a reasonable and positive manner [53]. However, in a context where excellence is the core business and a central defining feature of the workplace, where promotional competitions are tightly bound up with the language of excellence [54] and where, while presented as meritocratic, the assessment of that excellence is gendered [49], women are likely to be at much greater risk for identity threat, personal hurt and emotional damage.

I cannot over-emphasize the profound impact of these feedback sessions, coupled with the multiple "fix the women" sessions. To be told again and again that you must try harder, must do better, must secure (yet another) international collaborator, is offensive and hurtful in the extreme. No matter what you do, it is not enough. I saw the goalposts change again and again for me and for other women. As academics, we analyze. As female academics, we have subjected the gendered university, the biased structures and the chilly and hostile cultures to enlightened scholarly analysis. However, we also need to remember that there are people behind this analysis. We are those people. And we have been professionally and personally damaged by those processes.

\subsection{Theme 4: Solidarity}

Universities are curious organizations-I once heard them described as a loose affiliation of people united only in their complaints about the lack of parking spaces. They are probably best described as "professional bureaucracies" [55] where the expertise of the organization lies in the work of academics who are highly independent and while core aspects of the work process are standardized (recruiting students, teaching, etc.), central control is low, goals and output are based on personal expertise and differ for each professional. Neoliberal ideology notwithstanding, university culture is one that values independent thinking, freedom from political interference in research, and respects individual opinion and differences. Academics may identify more with their Profession or discipline and their allegiance to these may be stronger than to the institution. Structurally, they are fragmented and coordination can be a challenge [56]. By the same token, they are not given to collective action. Getting academics to "organize" would be very like herding cats.

When I took legal action, along with my four colleagues, we received very significant support from our colleagues, our students, our peers and our administrators, not forgetting the staff member in the canteen (a woman) who promised to bake a cake for the party when we won our cases. This was unexpected in an organization more divided than united in the main. The support was predominantly, but not exclusively, from women. This is an aspect of the "informal organization" not often acknowledged, where gender was a positive force.

Most significant was the donation from Dr. Joan Francis of her award (EUR 70,000) to help finance our cases. Joan worked tirelessly, promoting the cause and collecting funds should we need them in the event of going to Court. Her support was unwavering. In direct contrast to the denial and resistance from the mandarins of the gendered institution, the support from one woman was particularly poignant. Joan understood that the abuse inherent in gendered rules and regulations thrives in a culture of opaqueness and secrecy, normally unchallenged based on the perceived collective expertise of its members. By mounting a public campaign, she shone a light on the gendered practices of universities.

One particular event epitomized the undercurrent of support coursing through the university. Approaching the end of year 3 of litigation, colleagues decided we needed a shot in the arm in terms of support and collegiality, and organized a coffee morning, where people could meet and have a coffee with us to show their support. Over 300 attended. They tweeted the event and encouraged supporters everywhere to have a tea or a coffee with us wherever they were, that same morning, and to tweet the picture. This trended on Twitter had tweets from all over Ireland, and universities in Australia, Sweden and the UK. Female deputies in the Dáil (Irish parliament) tweeted their solidarity with us.

Critiques of the neoliberalization of universities bemoan the loss of collegiality. Collegiality of course was often collegiality only for white men, but nonetheless, we see it 
conceptually as something we lose when the agenda for new public management moves in. However, what I experienced from colleagues was a true collegiality.

\section{Conclusions}

So, how has this personalized account of gender discrimination added to our understanding of the gendered culture in HEIs, and the potential for changing it?

Seeing is important. Sinclair (2000) (cited in [57]) maintained that change in respect of gender inequality is only possible in an organization when gendered processes become visible through discrimination. Certainly, my experience demonstrated that surfacing gender discrimination, through legal action and a media campaign, stimulated change processes, but not before it was met with considerable resistance. To change a culture where those who stand to lose are those who have benefited from the previous regime, it is critical to realize those people will want to maintain their dominant position. To think otherwise is to be organizationally naïve. When it comes to gender, we may expect the principles of justice and fairness to obliterate power and politics, but should realize that they will not. Power and control, once held and enjoyed and used to maintain that comfortable position, will not be generously shared.

The glacial pace of change in respect of the under-representation of women in senior positions in HEIs has been noted repeatedly (e.g., [8,10,16,19-21,58]). My experience shows this to be due to resistance, and that resistance to be based on the unwillingness of the powerful (men) to accept that they have been biased and have created biased promotional processes. Instead, they divert attention to what women need to do to be permitted to enter the select club on the top floor, but cling tightly to their power which allows them to decide on who or how many to allow in.

Anger is important. Even when, as Sinclair acknowledges, gender discrimination is exposed sufficiently to demand change, people must make these demands. Women engage in a range of everyday practices: talking, teaching gender, valuing feminist research (e.g., [57]) and deliberate pragmatic strategies (e.g., [39]) to bring about change in their own institutions. Visible gender discrimination can act as a stimulus for change when it generates anger, and anger is the engine that drives those strategies and tactics. However, being angry is a challenge to the existing gender logic of appropriateness. In expressing it, women run the risk of being seen as deviant, odd or different, and being punished for this [8]. Female anger is a challenge to male power and thus, it serves the powerful (mostly men) in society and institutions well when it remains suppressed. Women who express anger in workplaces are penalized because such expression violates the prescriptive stereotype [59]. Finding voice and resisting silence in relation to gender inequality and sexism are immensely important when it happens, as recounted in the autoethnographic accounts of both Edwards and $\mathrm{O}^{\prime}$ Connor [38,39]. Not speaking up but waiting patiently for "your turn to come" (for promotion) is a hidden transcript that maintains hegemonic masculine power, and is a form of resistance to change [25]. Certainly, my silence can be seen as my internalization of familial messages that reflect societal and cultural expectations for women to stifle or sublimate anger [60,61]. Expressing anger can be empowering. When the cases were settled and I was finally promoted, there was a big celebratory party. I spoke that evening of my anger at the way I and so many other women had been treated. A colleague told me she was surprised but pleased to hear me "own" my anger, and not be afraid to say it. Anger helps reveal hidden transcripts and hidden power plays. We should not be afraid of it. In reading scholarly accounts of the extreme gender inequality in higher education, an inequality that impacts so profoundly on the professional careers of so many women, it is interesting that so many are dispassionate. Some of these excellent scholars must have experienced discrimination first hand and yet their work is deliberately leached of emotion. However, is this effort to display an objective, unemotional analysis not just another performance of learnt masculinities?

Data are important. The gendered regime operating in the Green University benefited from not reporting the numbers of lecturers promoted and not reporting the gender 
breakdown (figures have been reported at the Academic Council since the 2017 SLPS). Surprisingly, there are few models of organizational change that prioritize data as a lever for change (e.g., [62]). The significance of data was clearly acknowledged by the national Gender Task Force in their recommendations for year-on-year statistics on percentages of women in senior posts across Irish HEIs [63]. Data permit the quantification of a problem, which is a way of making a problem visible, that Sinclair maintains is essential for culture change with regard to gender inequality. It provides baselines, benchmarks and the opportunity to measure change. Data can also therefore make success visible. Data do not have to be "big" data; small data are often adequate for issues of social inclusion in organizations and are more accessible [64,65].

Women are important. The change brought about in the Green University was achieved by the actions of women. It may seem self-evident that the people who lead change are the people for whom change is needed. Arguably, the gendered culture will be visible to women more rapidly and with greater clarity than men. Yet, in this account, women also played other key roles, in particular seeing the need for additional support and finding inventive ways of providing it. The Green University, at the time of my litigation, was characterized by a culture of fear. Lots of people took risks to help bring about a measure of change. There were men as well as women, but for the women (most of whom were still not promoted themselves), the risk was greater. Joan, the plaintiff in the Equality case, is a small woman, about $5^{\prime} 2$ in height. I marveled and relished how she brought an entire institution to account. Sometimes it is just about courage and the conviction that justice should prevail.

Burkinshaw (2015) (cited in [19]) talks of leadership in HEIs involving a performance of masculinities in order to gain membership to an elite hegemonic masculinist community. Promotional processes in HEIs are part of this process. Women are "permitted" to enter, once they have been trained and mentored into the masculinist way of being in the university - competitive, opportunistic, self-promoting. In doing this, we are simply reproducing the biased, gendered systems that created the problem in the first place. HEIs are increasingly submerged in the "logic" of competitiveness. Achieving gender equality is not just about getting more women at the top. It is about calling out and challenging this destructive ideology.

Funding: This research received no external funding.

Institutional Review Board Statement: Not applicable.

Informed Consent Statement: Not applicable.

Data Availability Statement: Not applicable.

Conflicts of Interest: The authors declare no conflict of interest.

\section{References}

1. European Commission. SHE Figures 2018; European Commission: Brussels, Belgium, 2019; Available online: https: / /ec.europa. eu/info/publications/she-figures-2018_en (accessed on 18 December 2020).

2. Goransson, A. Gender Equality and the Shift from Collegiality to Managerialsm. In Gender, Power and Management: A Cross Cultural Analysis of Higher Education; Bagilhoe, B., White, K., Eds.; Palgrave Macmillan: Basingstoke, UK, 2011.

3. HEA. Higher Education Institutional Staff Profiles by Gender; HEA: Dublin, Ireland, 2016.

4. HEA. Higher Education Institutional Staff Profiles by Gender; HEA: Dublin, Ireland, 2020.

5. HEA. Higher Education Institutional Staff Profiles by Gender; HEA: Dublin, Ireland, 2017.

6. HEA. Higher Education Institutional Staff Profiles by Gender; HEA: Dublin, Ireland, 2018; Available online: https://hea.ie/2017/07/ 19/report-on-higher-education-institutional-staff-profiles-by-gender-published/ (accessed on 31 January 2021).

7. Quinlavan, S. Disrupting the Status Quo? Discrimination in Academic Promotions. Ir. Employ. Law 2017, 14, 68-75.

8. Chappell, L.; Waylen, G. Gender and the Hidden Life of Organisations. Public Adm. 2013, 91, 599-615.

9. Acker, J. The Future of "Gender and Organisations": Connections and Boundaries. Gend. Work Org. 1998, 5, 195-206. [CrossRef]

10. O'Connor, P. Why is it so difficult to reduce gender inequality in male-dominated higher educational organisations? A feminist institutional perspective. Interdiscip. Sci. Rev. 2020, 45, 207-228. [CrossRef] 
11. O'Connor, P.; Carvalho, T.; Vabø, A.; Cardoso, S. Gender in Higher Education: A Critical Review. In The Palgrave International Handbook of Higher Education Policy and Governance; Palgrave Macmillan: Basingstoke, UK, 2015; pp. 569-584.

12. Janicijevic, N. Methodological approaches in the research of organisational culture. Econ. Ann. 2011, 56, 69-99. [CrossRef]

13. Meek, V.L. Organisational Culture: Origins and Weaknesses. Org. Stud. 1988, 9, 453-473. [CrossRef]

14. Bellot, J. Defining and Assessing Organizational Culture. Nurs. Forum 2011, 46, 29-37. [CrossRef]

15. Etheridge, L. The Trouble with Culture: An Interpretive Case Study of Organisational Culture, Learning and Quality Improvement in the National Health Service. Ph.D. Thesis, University of London, London, UK, 2014.

16. Morley, L. Hidden transcripts: The micropolitics of gender in Commonwealth Universities. Women's Stud. Int. Forum. 2006, 29, 534-551. [CrossRef]

17. Deem, R. Gender, Organisational Cultures and the Practices of Manager-Academics in UK Universities. Gend. Work Org. 2003, 10, 239-259. [CrossRef]

18. Coate, K.; Howson, C.K. Indicators of esteem: Gender and prestige in academic work. Br. J. Sociol. Educ. 2014, 37, 567-585. [CrossRef]

19. O'Connor, P. Gender imbalance in senior positions in higher education: What is the problem? What can be done? Policy Rev. High. Educ. 2019, 3, 28-50. [CrossRef]

20. van den Brink, M.; Benschop, Y. Slaying the seven-headed dragon: The quest for gender change. Gend. Work Org. 2012, 19, 71-92. [CrossRef]

21. O'Connor, P. Where Do Women Fit in University Senior Management? An Analytical Typology of Cross-National Organisational Cultures; Bagilhole, B., White, K., Eds.; Palgrave McMillan: London, UK, 2011; pp. 168-191.

22. By, R.T. Organisational Change Management: A Critical Review. J. Change Manag. 2005, 5, 369-380. [CrossRef]

23. Balugun, J.; Hope, H.V. Exploring Strategic Change; Prentice Hall: London, UK, 2004.

24. Gwanka, A.A.; Gidion, O.C.; Mayianda, R.; Damaris, K.A. Organisational Change: A Critical Review of the Literature. Int. Prof. Appl. Manag. Rev. 2016, 11, 1-6.

25. Agócs, C. Institutionalized Resistance to Organizational Change: Denial, Inaction and Repression. J. Bus. Ethics 1997, 16, 917-931. [CrossRef]

26. Thomas, R.; Hardy, C. Reframing resistance to organizational change. Scand. J. Manag. 2011, 27, 322-331. [CrossRef]

27. Lombardo, E.; Mergaert, L. Gender Mainstreaming and Resistance to Gender Training: A Framework for Studying Implementation. NORA Nord. J. Fem. Gend. Res. 2013, 21, 296-311. [CrossRef]

28. Hodgins, M.; MacCurtain, S.; Mannix-McNamara, P. Power and inaction: Why organizations fail to address workplace bullying. Int. J. Work. Health Manag. 2020, 13, 265-290. [CrossRef]

29. Hodgins, M.; McNamara, P.M. An Enlightened Environment? Workplace Bullying and Incivility in Irish Higher Education. SAGE Open 2019, 9. [CrossRef]

30. Bacharach, S.B.; Baratz, M.S. The two faces of power. Am. Polit. Sci. Rev. 1962, 56, 947-952. [CrossRef]

31. Lukes, S. Power: A Radical View; Palgrave Macmillan: Basingstoke, UK, 1974.

32. Gaventa, J. Power and Powerlessness. Quiescence and Rebellion in an Appalachian Valley; University of Illinois Press: Chicago, IL, USA, 1980.

33. O'Connor, P. Management and Gender in Higher Education; Manchester University Press: Manchester, UK, 2014.

34. Montez Lopez, E.; O'Connor, P. Micropolitics and meritocracy: Improbable bedfellows? Educ. Manag. Adm. Leadersh. 2019, 47, 678-693. [CrossRef]

35. Davies, H.T.O.; Nutley, S.M.; Mannion, R. Organisational culture and quality of health care. Qual. Health Care 2000, 9, 111-119. [CrossRef]

36. Pelias, R.J. The Academic Tourist: An Autoethnography. Qual. Inq. 2003, 9, 369-373. [CrossRef]

37. Hernandez, K.-A.C.; Ngunjiri, F.W.; Chang, H. Exploiting the margins in higher education: A collaborative autoethnography of three foreign-born female faculty of color. Int. J. Qual. Stud. Educ. 2014, 28, 533-551. [CrossRef]

38. Edwards, J. Narrating experiences of sexism in higher education: A critical feminist autoethnography to make meaning of the past, challenge the status quo and consider the future. Int. J. Qual. Stud. Educ. 2017, 30, 621-634. [CrossRef]

39. O'Connor, P. An autoethnographic account of a pragmatic inclusionary strategy and tactics as a form of feminist activism. Equal. Divers. Incl. Int. J. 2019, 38, 825-840. [CrossRef]

40. Ellis, C.; Adams, T.; Bochner, A. Autoethnography: An overview. Forum Qual. Sozialforschung. 2011, 12, 10.

41. Chang, H. Autoethnography as Method; Left Coast Press: Walnut Creek, CA, USA, 2008.

42. Poerwandari, E.K. Minimizing Bias and Maximizing the Potential Strengths of Autoethnography as a Narrative Research. Jpn. Psychol. Res. 2021. [CrossRef]

43. Méndez, M.G. Autoethnography as a research method: Advantages, limitations and criticisms. Colomb. Appl. Linguist. J. 2014, 15, 279-287. [CrossRef]

44. O'Connor, P.; Irvine, G. Multi-level State Interventions and Gender Equality in Higher Education Institutions. Ir. Case Adm. Sci. 2020, 10, 98. [CrossRef]

45. O'Connor, P. Our university promotions system is designed by men for men. The Irish Times. Available online: https://www. irishtimes.com/news/education/our-university-promotions-system-is-designed-by-men-for-men-1.4168551 (accessed on 20 February 2020). 
46. Keiser, R.L.; Bachrach, P.; Baratz, M.S. Power and Poverty: Theory and Practice. Man 1972, 7, 516. [CrossRef]

47. Mulder, P. Lewin's Change Model 2012. Available online: https://www.toolshero.com/change-management/lewin-changemanagement-model/ (accessed on 31 January 2021).

48. Rees, T. The Gendered Construction of Scientific Excellence. Interdiscip. Sci. Rev. 2011, 36, 133-145. [CrossRef]

49. O'Connor, P.; O'Hagan, C. Excellence in university academic staff evaluation: A problematic reality? Stud. High. Educ. 2016, 41, 1943-1957. [CrossRef]

50. Vitesse, T. Sexism in the Academy. 2019. Available online: https://nplusonemag.com/issue-34/essays/sexism-in-the-academy/ (accessed on 7 March 2020).

51. Lutgen-Sandvik, P. Intensive Remedial Identity Work: Responses to Workplace Bullying Trauma and Stigmatization. Organization 2008, 15, 97-119. [CrossRef]

52. Giddens, A. Modernity and Self-Identity; Stanford University Press: Stanford, CA, USA, 1991.

53. Alvesson, M.; Willmott, H. Identity Regulation as Organizational Control: Producing the Appropriate Individual. J. Manag. Stud. 2002, 39, 619-644. [CrossRef]

54. Harzing, A.-W. London School Economics 2018. Available online: https://blogs.lse.ac.uk/impactofsocialsciences/2018/09/28 /internal-vs-external-promotion-part-one-seven-reasons-why-external-promotion-is-easier/ (accessed on 7 March 2020).

55. Mintzberg, H. The Structuring of Organizations; Prentice Hall: New Jersey, NJ, USA, 1979.

56. Sporn, B. Managing university culture: An analysis of the relationship between institutional culture and management approaches. High. Educ. 1996, 32, 41-61. [CrossRef]

57. Culture and Management Approaches. High. Educ. Res. Dev. 1996, 32, 41-61.

58. Parsons, E.; Priola, V. Agents for Change and Change Agents: The Micro-politics of Change and Feminism in the Academy. Gend. Work Org. 2013, 20, 580-597. [CrossRef]

59. Crimmins, G. Strategies for Resisting Sexism in the Academy_Higher Education, Gender and Intersectionality; Palgrave Macmillan: Cham, Switzerland, 2019.

60. Marshburn, C.K.; Cochran, K.J.; Flynn, E.; Levine, L.J. Workplace Anger Costs Women Irrespective of Race. Front. Psychol. 2020, 11, 3064. [CrossRef]

61. Stock-Ward, S.R. Women and Anger: The Roles of Gender, Sex Role, and Feminist Identity in Women's Anger Expression and Experience; Iowa State University: Ames, IA, USA, 1995.

62. Chemaly, S. Rage Becomes Her: The Power of Women's Anger; Atria: New York, NY, USA, 2018.

63. Mulholland, B. 8 Critical Change Management Models to Evolve and Survive: Process.st. 2017. Available online: https://www. process.st/change-management-models/-Lewin \T1 \textquoterights-change-management-model (accessed on 2 February 2021).

64. HEA. HEA National Review of Gender Equality in Irish Higher Education Institutions; Higher Education Authority: Dublin, Ireland, 2016.

65. Lai, J. Lessons Learned on the Role of Data in Driving Change and Inclusion n.d. Available online: https://www.aug.co/blog/ lessons-learned-on-the-role-of-data-in-driving-change-and-inclusion (accessed on 22 March 2021). 